\title{
THE NO-RETRACTION PRINCIPLE AND THE MORALITY OF NEGOTIATIONS
}

\section{DANIEL MARKOVITS ${ }^{\dagger}$}

The central philosophical puzzle about contract law involves the ground upon which contractual obligation arises. Omri Ben-Shahar's intriguing essay, Contracts Without Consent: Exploring a New Basis for Contractual Liability, ${ }^{1}$ proposes a new theory of contractual liability and contains the seeds of an appealing new approach to this puzzle. In place of the traditional agreement-based conception of contractual liability under which, as Ben-Shahar says, "a contract forms only when the positions of the two parties meet," Ben-Shahar proposes a new regime. His proposal imagines that offers and counteroffers generate a converging sequence of liability, under the principle that "[a] party who manifests a willingness to enter into a contract at given terms should not be able to freely retract from her manifestation." "Ben-Shahar's contribution to the philosophical foundations of contract does not figure prominently in his own presentation of this principle of "noretraction," however, which emphasizes an economic approach. ${ }^{4}$ Indeed, Ben-Shahar expressly admits that "[i]t is beyond the scope of [his] Essay to inquire into the philosophical underpinnings of the non-rejectability of an individual's own representations." I shall therefore devote these pages to bringing out some of the philosophical

\footnotetext{
'Associate Professor of Law, Yale Law School.

1 Omri Ben-Shahar, Contracts Without Consent: Exploring a New Basis for Contractual Liability, 152 U. PA. L. REV. 1829 (2004).

${ }^{2}$ Id. at 1829. Ben-Shahar is, of course, aware that the modern law of contract has abandoned the "mirror image" rule and that it is now willing to imply contract terms when the parties' conduct recognizes the existence of a contract in spite of nonconforming communications. He explains why this regime remains critically different from the regime he proposes. See id. at 1870 (differentiating between contracts under the Uniform Commercial Code, which continues to insist on binding both parties to the same terms-although under a much more flexible regime than the mirror image rule-and contracts under a no-retraction regime, in which nonconforming communications are "baselines that each party sets for the other to accept").

${ }^{3}$ Id. at 1830.

${ }^{4}$ See id. at 1871 ("The analysis in this Essay focuses on one type of justification for the no-retraction liability regime, namely, an economic justification emphasizing reliance incentives.").

${ }^{5}$ Id. at 1840 n. 20.
} 
ideas that are immanent in Ben-Shahar's view but that are not emphasized in his own account of this view. Although these ideas differ markedly from my approach to the philosophical foundations of contract, ${ }^{6}$ I shall not, in the main, try to test Ben-Shahar's views against my own. I prefer, instead, to present a sympathetic reconstruction of Ben-Shahar's position.?

I begin by briefly explaining the philosophical puzzle about the foundations of contractual liability. Next, I discuss the elements of Ben-Shahar's essay that most conspicuously address the puzzle and argue that these efforts to connect the no-retraction principle to the grounds of contract liability represent wrong turnings in the philosophical analysis of no-retraction liability and distract from the proposal's true promise. Finally, I introduce a more auspicious connection between the no-retraction principle and the grounds of contractual liability and connect it to some of Ben-Shahar's own observations and examples. Although I shall not seek to develop this positive account in any detail, I do hope to lay out its main lines with sufficient clarity to reveal its potential.

\footnotetext{
${ }^{6} 1$ develop this approach in Daniel Markovits, Contract and Collaboration, 113 YAlE L.J. 1419 (2004).

${ }^{7}$ I also prefer to reconstruct Ben-Shahar's position in a way that renders it philosophically distinctive. Thus, I shall not pursue the narrowest philosophical interpretation of the no-retraction thesis that is invited by Ben-Shahar's essay, namely that it instigates an intramural dispute with the contractualist moral theory proposed by T. M. Scanlon. Scanlon applies this theory, which seeks to develop moral principles that no one could reasonably reject as the basis for informed, unforced general agreement about regulating behavior among persons motivated to seek such agreement, to the morality of promise and contract to generate a more or less orthodox substantive view of these obligations. See T. M. SCANLON, What WE OWE TO EACH OTHER 295-327 (1998) (developing a contractualist account of promissory obligation); T. M. Scanlon, Promises and Contracts, in THE THEORY OF CONTRACT LAW: NEW EsSAYS 86 (Peter Benson ed., 2001) (developing a contractualist account of contract law); Thomas Scanlon, Promises and Practices, 19 PHIL. \& PUB. AFF. 199 (1990) (developing a contractualist account of promissory obligation). One might read Ben-Shahar, who refers to Scanlon's idea of reasonable rejection, Ben-Shahar, supra note 1 , at $1840 \mathrm{n} .20$, as proposing that Scanlon has misapplied his own theory and that a focus on reasonable rejection in fact generates no-retraction liability, rather than orthodox contract. I do not think that this is the best interpretation of Ben-Shahar's argument, however. To begin with, BenShahar does not in fact proceed in a contractualist mode, and his invocation of reasonable rejection seems to constitute a philosophical red herring. More importantly, the substance of Ben-Shahar's view tends, as I shall hope to show, toward a very different, and much more philosophically novel, reconstruction of the grounds of contract.
} 


\section{ThE GRounds of CONTRACT}

Many different types of obligation typically arise in connection with contractual promises. ${ }^{8}$ A promisee may make a payment or other return performance in exchange for a contractual promise that remains executory, and a contractual promisor may incur restitutionary obligations in connection with receiving such benefits from her promisee. Similarly, a promisee may reasonably incur costs (including opportunity costs) in anticipation of a promised performance, and a contractual promisor may incur tort-like obligations in connection with her promisee's reasonable reliance. But contract may also stand unadorned by restitution or tort, as it does when contractual promisors have received no benefits and their promisees have incurred no costs. Moreover, this freestanding conception of contract accords with our practical experience of contractual obligation. It receives doctrinal expression, for example, in the fact that contractual liability (unlike the liability for misrepresentations that arise in restitution or tort) is strict liability. The freestanding conception is also reflected in the expectation remedy, which enforces contractual obligation entirely apart from any enrichment in the promisor or harm in the promisee.

The grounds of freestanding contractual obligation-of contract unbacked by restitution or tort-remain deeply mysterious, however. Contractual obligation must rest, in such cases, solely upon the force of the contractual promise itself, on the intentions-the state of willthat this promise involves. But the contractual promisor's will to be bound, standing alone, seems too slight to support legal obligation. To be sure, persons may incur obligations in conjunction with wilful actions in any number of ways, as they commonly do when their intentional actions, including perhaps representations of how they will act in the future, harm others. But the obligations that arise in all these cases are grounded in the effects that the actions in question have on others-in the harms that they do-and not in the bare willing in itself. Persons do not simply will these obligations into existence, as they would have to do in cases of contract unbacked by restitution or reliance. And it is hard to see how contractual obligation could possibly arise in this way because it is incredible that the will, on its

${ }^{8}$ This discussion follows a longer argument that I present in Contract and Collaboration, Markovits, supra note 6, at 1435-46. That argument not only sets out the philosophical puzzle concerning the grounds of contract, but also develops my own preferred solution to the puzzle. 
own, could conjure into existence anything so substantial as an obligation.

Indeed, even though contracts are among the commonest instances of legal obligation (and even though every child knows that promises must be kept), the question how such obligations are created presents a familiar puzzle in moral philosophy. It is at least as old as David Hume, who compared the idea that promissory obligation might arise out of the bare act of will involved in making a promise to the mystery of transubstantiation. ${ }^{9}$ Moreover, although they have not generally received such a philosophical expression, these concerns have not been lost on contract lawyers, who have also long displayed uncertainty about the foundations of purely contractual obligation. The canonical statement of this uncertainty appears in Lon Fuller and William Perdue's classic article, The Reliance Interest in Contract Damages, ${ }^{10}$ which observes that, when a contract claim asserts expectations that are unbacked by either restitution- or reliance-based claims, the "justification for legal relief loses its self-evident quality.""

Such worries have led both philosophers and lawyers to retreat from regarding contract as a freestanding class of obligation and to seek, instead, to assimilate contract into forms of obligation that stand on ground more solid than the promissory will. These views accept that the willing of a promise may trigger contractual obligation, but they no longer require the will to underwrite it. The most prominent philosophical efforts in this direction seek to ground contractual obligation either in the harm done to promisees who have reasonably relied on contractual promises or in the social utility of the practice of enforcing such obligations. ${ }^{12}$ The most prominent legal efforts, unsurprisingly, take up both themes and bring them to bear on contract doctrine including the doctrines that appear to express contract's freestanding, promissory character. Fuller and Perdue, for example,

9 David Hume, A Treatise of Human Nature, bk. 3 , pt. $2, \S 5$, at 524-25 (L. A. Selby-Bigge \& P. H. Nidditch eds., Oxford Univ. Press 2d ed. 1978) (1739-1740).

${ }^{10}$ L. L. Fuller \& William R. Perdue, Jr., The Reliance Interest in Contract Damages (pts. 1-2), 46 YALE L.J. 52, 373 (1936-1937).

${ }^{11} I d$., pt. 1 , at 57 . A similar view appears in P. S. ATIYAH, PROMISES, MORALS, AND LAW 16-17 (1981).

${ }_{12}$ The first, harm-based account appears, for example, in Neil MacCormick, Vol untary Obligations and Normative Powers (pt. 1), 46 ARISTOTElian SOC'Y 59, 62 (Supp. 1972) (" $[R]$ eliance on the promisor is sufficient ground for asserting that the promisor has an obligation to keep his word."). The second, practice-based account is Hume's own view. See Humk, supra note 9 , bk. 3, pt. $2, \S 5$, at 516 ("[A] promise wou'd not be intelligible, before human conventions had establish'd it; and ... even if it were intelligible, it wou'd not be attended with any moral obligation." (emphases omitted)). 
take up the first theme when they attempt to recast the expectation remedy in terms of harm and reliance. They claim that the expectation interest is most securely protected by courts in connection with business contracts-that is, contracts made by parties who have foregone other opportunities to make them. ${ }^{19}$ When thick markets exist, these foregone opportunities will be only marginally less valuable to promisees than the contract they in fact made so that their contractual expectations may also be recast in terms of reliance losses-that is, the opportunity costs of not dealing with alternative promisors. ${ }^{14}$ The economic approach to contract takes up the second theme when it emphasizes the efficiency of the expectation remedy and suggests, on this basis, that protecting contractual expectations maximizes the social value of the practice of contract. ${ }^{15}$

These reductive approaches purport to explain contractual obligation without invoking any mysterious powers of the will. But they achieve this solidity only by distorting contractual practice-by emphasizing the forms of obligation that commonly arise around contract while repressing contract's characteristic core. The reductive approaches are embarrassed by the practical experience of contract, which does not defer to alternative forms of obligation or to the social utility of contractual practice as the reductive approaches require. Thus, the law acknowledges—but does not depend upon-detrimental reliance by promisees so that it will (as Fuller and Perdue themselves admit) ${ }^{16}$

${ }^{13}$ Fuller \& Perdue, supra note 10, pt. 1, at 60.

${ }^{14}$ See id. at 60-66 (developing this reliance-based explanation for courts' protection of the expectation interest).

${ }_{15}$ The efficiency of expectation damages was introduced into the legal literature by Robert L. Birmingham, Breach of Contract, Damage Measures, and Economic Efficiency, 24 RUTGERS L. REV. 273 (1970). This remedy has been much investigated since, and although expectation damages are efficient with respect to many decisions in many circumstances, see, e.g., Richard Craswell, Contract Remedies, Renegotiation, and the Theory of Efficient Breach, 61 S. CAL. L. REV. 629 (1988) (discussing the efficiency of the expectation remedy), it is now well understood that they are not efficient with respect to all decisions in all circumstances, see, e.g., Steven Shavell, Damage Measures for Breach of Contract, 11 BELL J. ECON. 466, 472 (1980) (arguing that expectation damages, even in conjunction with a mitigation principle, can induce inefficient overreliance). The connection (or disconnect) between economic efficiency and social value is, of course, itself a fraught question. See, e.g., Richard S. Markovits, On the Relevance of Economic Efficiency Conclusions, 29 FLA. ST. U. L. REV. 1, 26-43 (2001) (contending that economic efficiency does not by itself support moral conclusions).

${ }^{16}$ See Fuller \& Perdue, supra note 10, pt. 1, at 62 ("[I]t has been found wise to make recovery on a promise independent of reliance, both in the sense that in some cases the promise is enforced though not relied on ... and in the sense that recovery is not limited to the detriment incurred in reliance."). Fuller and Perdue do go on to 
enforce contractual expectations that are not backed by these other forms of obligation. ${ }^{17}$ Moreover, the law emphasizes the formal-category expectation damages in ways that, as Richard Craswell has observed, cannot be explained by any instrumental connection between the substance of expectation damages and economic efficiency. ${ }^{18}$ Finally, and perhaps most importantly, the practical experience of contract identifies an obligation that functions, as Joseph Raz argues, precisely to remove the decision to perform contracts from the overall calculus of these alternative values so that we feel bound to keep our contracts even when doing so does not best prevent harm, maximize social utility, or promote the best consequences overall. ${ }^{19}$

Efforts to recast contract in terms of harm or social welfare therefore do not so much explain our practical experience of contract as explain it away. This accounts for the fact that theories that treat contract as a freestanding form of obligation, rooted in the states of will of persons who engage it, enjoy an enduring appeal in spite of their mysterious nature.

\section{TWO DEFLATIONARY APPROACHES}

Ben-Shahar expressly insists that, although no-retraction liability may resemble tort liability (presumably most closely resembling liability for

claim that the law's tendencies in this direction are limited and may be explained from within the reliance view. Id. at 65 .

${ }^{17}$ This occurs, for example, when the law enforces commercially unrealistic warranties, which create expectations unbacked by any reliance (including by any opportunity costs) because the exaggerated character of such warranties makes them much more attractive to buyers than the available alternatives. See, e.g., Chatlos Sys., Inc. v. Nat'l Cash Register Corp., 670 F.2d 1304, 1307 (3d Cir. 1982) (enforcing a warranty that a computer system priced at approximately $\$ 50,000$ would perform tasks that no commercially available system priced below $\$ 208,000$ could perform and awarding expectation damages, unbacked by reliance, based on the $\$ 208,000$ value of the system as warranted). Admittedly, the law does not always enforce such warranties. See, e.g., Overstreet v. Norden Labs., Inc., 669 F.2d 1286, 1296 (6th Cir. 1982) (Engel \& Kennedy, JJ., concurring) (declining, over vigorous dissent, to enforce a warranty that a vaccine would protect horses from a disease, in part because no other vaccine existed, so that the buyer's horses were not lost to the disease in reliance on the warranty).

${ }^{18}$ See Richard Craswell, Against Fuller and Perdue, 67 U. CHI. L. REv. 99, 138-54 (2000) (arguing that the efficient remedy will not generally match the formal measure established by the expectation interest and that, if such matches do arise, they will be coincidental only).

${ }^{19}$ See J. Raz, Promises and Obligations, in LAW, MORALITY, AND SOCIETY: ESSAYS IN HoNOUR OF H. L. A. HART 210, 225-26 (P. M. S. Hacker \& J. Raz eds., 1977) (discussing the formal structure of the reasons for promise-keeping and how these reasons figure in practical deliberations). 
the tort of misrepresentation, a comparison to which I shall return in a moment), it is in fact a species of will-based, freestanding contract. ${ }^{20}$ He insists that "it is nonetheless the will of a party ... that ignites [noretraction] liability," and he contemplates that no-retraction liability might give rise to distinctively contractual, expectation-based remedies in appropriate circumstances. ${ }^{22}$ Furthermore, although Ben-Shahar never makes the connection explicit, and although he takes up the question of the grounds of no-retraction obligation only interstitially, two quite prominent themes in his account may be understood as efforts to explain why no-retraction liability is proof against the anxiety that other will-based views of contract produce.

Both efforts share a deflationary impulse: Rather than arguing that the will does indeed possess the potency to underwrite contractual liability whose need for grounding remains undiminished, BenShahar proposes that no-retraction liability is not as mysterious as it might seem so that the search for its ground is not as pressing as might be supposed. I doubt that either of these deflationary approaches can possibly succeed, but it is nevertheless worth identifying their appearances in Ben-Shahar's essay and working through their shortcomings. Doing so will forestall certain attractive confusions. More importantly, this exercise will lead naturally to a third approach to the puzzle about the grounds of contract, which is less welladvertised in Ben-Shahar's analysis but more deeply intertwined with the basic structure of his view and which presents a new and promising beginning.

The first of Ben-Shahar's deflationary proposals emphasizes what he calls " $[t]$ he gradual rise of liability under the no-retraction principle." ${ }^{23}$ Thus, Ben-Shahar "view[s] [no-retraction] liability as a process of continuous convergence" ${ }^{24}$ and proposes that no-retraction liability "provides a new underpinning" ${ }^{25}$ for Lon Fuller's proposal to "break[] down the contract-no contract dichotomy, and substitute[] an ascending scale of enforceability." ${ }^{26}$ The result of this process of convergence,

\footnotetext{
${ }^{20}$ Ben-Shahar, supra note 1 , at 1835.

${ }^{21}$ Id.

${ }^{22}$ Id. at $1844-45$.

23 Id. at 1860.

${ }^{24}$ Id. at 1831.

${ }^{25}$ Id.

${ }^{26}$ Letter from Lon L. Fuller to Karl N. Llewellyn, Professor of Law, Columbia University (Dec. 8, 1938), excerpted in ROBERT S. SUMmers \& ROBERT A. HILlMAN, CoNtract and Related Obligation: Theory, Doctrine, and PRACTICE 41 (4th ed.
} 
according to Ben-Shahar, is that "the greater the 'fraction' of a contract the parties have, the greater the 'fraction' of contract liability the plaintiff can enforce." ${ }^{27}$ Under no-retraction liability, the parties' wilful engagement with their contract-their will to be bound-"exhibits [a] gradual ascent" that proceeds in parallel to the gradual development of contractual liability. ${ }^{28}$ At the start of negotiations, when the parties' positions remain far apart, "their will to be bound is weak,"29 and not much liability exists. Then, as negotiations continue and the parties' positions converge, "their will to be bound increases," their liability, passing through "intermediate"31 stages before finally achieving the completed contract. In this way, Ben-Shahar suggests that the no-retraction view requires the will to be bound to ground full-fledged contractual liability only after the parties have passed through "an intermediate species of liability." 32 And just as many small weights are easier to carry than a single large one, so the will may seem more capable of underwriting the many small steps in this gradual development of liability than of grounding full contractual obligation all at once.

This proposal cannot succeed, however, because the image of "an ascending scale of enforceability" mischaracterizes the progress of noretraction liability. The image suggests that somehow the arguments for enforcement increase as the parties' negotiations converge on a final agreement, and in Fuller's own case-presumably involving the chain from purely expectation-, to reliance-, to restitution-based liability-something very much like this is plausibly at play. ${ }^{39}$ As Fuller and Perdue observe, the expectation interest involves a "promisee who merely demands satisfaction for his disappointment in not getting what was promised him," while the reliance interest, which involves a promisee who has been harmed, "presents a more pressing case for relief," and the restitution interest, "involving a combination of unjust impoverishment with unjust gain, presents the strongest case

2001). Ben-Shahar repeatedly refers to Fuller's "scale of enforceability." Ben-Shahar, supra note 1 , at $1831 \& \mathrm{n} .1,1836,1859,1871$.

${ }^{27}$ Ben-Shahar, supra note 1 , at 1831.

${ }^{28}$ Id. at 1836 .

${ }^{29} I d$.

${ }^{30} \mathrm{Id}$.

31 Id. at 1859 .

${ }^{32} I d$. at 1871 .

33 See Letter from Lon L. Fuller to Karl N. Llewellyn, supra note 26, at 41 (discussing "an ascending scale of enforceability" that runs "from restitution through the reliance interest to the expectation interest"). 
for relief." ${ }^{34}$ Each interest strengthens the obligation at issue by adding a new argument or foundation for this obligation. But there is nothing analogous at work in Ben-Shahar's converging chain of noretraction liability. Although, as Ben-Shahar says at one point, "the effective burden of this type of liability increases gradually" as the parties progress toward agreement, ${ }^{35}$ no new arguments for liability are added at all, and the quality of liability remains unchanged. Noretraction liability is grounded in the same way at every step in the chain, namely by the liable party's manifested willingness to contract at the terms to which it is being held. The incremental character of no-retraction liability therefore cannot dampen the anxiety about the will's capacity to ground obligation at all, and this anxiety applies unabated to Ben-Shahar's view.

Ben-Shahar also presents a second argument that might defuse anxiety about the will's capacity to ground no-retraction liability. He observes that the no-retraction principle may be applied against a party only when "it can confidently be said that this party manifested her 'constructive' intent to be bound" to the terms that the principle imposes, ${ }^{36}$ and he suggests, on this basis, that no-retraction liability may safely be imposed on a party "without bending her will." Moreover, Ben-Shahar consistently fleshes out his account of the no-retraction principle in ways that are designed to preserve its claim to being unobjectionable in this way. For example, he seeks to prevent persons from being improperly swept into the regime, specifically by insisting that no-retraction liability arises against a party only when a "representation provides enough detail to infer that party's intent to contract under its terms." ${ }^{38}$ And he argues that no-retraction liability should fill gaps in incomplete representations with terms that are as favorable as reasonably possible to the liable party ${ }^{39}$ so that the no-retraction principle never imposes liability on any other than the most attractive terms the liable party could plausibly imagine. ${ }^{40}$ Ben-Shahar attempts,

${ }^{34}$ Fuller \& Perdue, supra note 10, pt. 1, at 56.

${ }^{35}$ Ben-Shahar, supra note 1, at 1842 (emphasis added).

${ }^{36}$ Id. at 1841 .

${ }^{37}$ Id.

${ }^{38} I d$. at 1844

${ }^{39}$ Id. at $1845-47,1864-65$.

${ }^{40} I d$. at 1831. Ben-Shahar intimates, in this connection, that the no-retraction principle avoids difficulties that famously trouble will-based accounts of traditional contract liability. He observes that the traditional doctrine also fills the gaps in incomplete contracts, although with terms (typically involving majority defaults or information-forcing penalty defaults) that are not specifically designed to be unobjectionable to the liable 
in this way, to avoid questions of the will's capacity to ground noretraction obligation by means of an estoppel-like argument. He suggests, in effect, that a promisor cannot object to an effort to hold her to the most favorable construction that may reasonably be given to the terms she herself proposed. On this argument, the will need not display much potency in order to ground no-retraction liability because this liability, which imposes only terms that the liable party herself proposed, imposes no real constraints and so needs little grounding. ${ }^{41}$

The trouble with this argument is that no-retraction liability applies even, and indeed characteristically, to persons who no longer want to be held to the terms that they once proposed. The noretraction principle, as its very name suggests, prevents people from changing their minds so that the obligations created by the regime that Ben-Shahar recommends therefore genuinely do constrain those to whom they apply, and this constraint must be grounded in some way. Moreover, and critically, the no-retraction principle applies quite apart from the reasons for which a person has made or seeks to retract a proposal. It applies, in particular, even in the absence of bad faith or negligence-even against persons who have conducted themselves impeccably in connection with their contractual representations and wish to retract them, for example, only because of unanticipated events. No-retraction liability, like contract liability quite generally but unlike tort liability for misrepresentation, is strict liability; it does not depend on the negligence or bad faith of the retractor. ${ }^{42}$ Noretraction liability consequently cannot be grounded by observing that

party. The deflationary argument that Ben-Shahar presents therefore does not apply as successfully to traditional contract law as to the no-retraction principles he develops.

${ }^{41}$ This argument suggests that Contracts Without Consent is a misleading title for Ben-Shahar's essay, since one of his themes is that parties who are held liable under the no-retraction principle have in fact consented to the terms of their liability. BenShahar's approach is distinctive not because it does without consent altogether but because it is satisfied with one-sided consent: As he observes, no-retraction liability is triggered not by "the convergence of two wills," but by "the manifestation of only one will." Id. at 1838. In light of this approach, it would be more accurate to title the essay Contracts Without Agreement or perhaps Contracts Without Consensus.

${ }^{42}$ Ben-Shahar sometimes writes as if to deny this, as when he focuses on examples of bad faith contractual representations or bad faith retractions, id. at 1860-61, or when he claims that, if one party has made a promissory representation and "the other party caves in and concedes all the contested issues, ... then the refusal of this party to finalize a deal can be construed as bad faith conduct," id. at 1861. But Ben-Shahar, who clearly and expressly does not take himself to be providing an analysis of torts involving misrepresentation, see supra text accompanying note 20 (acknowledging Ben-Shahar's express insistence on a characterization of no-retraction liability as a type of freestanding contract), cannot regard his no-retraction principle as limited to cases of bad faith. 
retracting contractual representations is wrong in these familiar ways because it applies even in the absence of such wrongs.

Although Ben-Shahar claims that liability, under his approach, "results from a unilateral wrongful action of a party[,] . . retraction from a representation," wrongfulness of a good faith, non-negligent retraction remains precisely what is at issue. This is the wrong that theories of pure promissory obligation must somehow explain by reference to the will of the contractual promisor, and with respect to which the familiar anxiety over the will's power to ground such obligation takes hold. BenShahar's theory of no-retraction liability is as much in need of grounding the obligation it proposes, and as subject to this anxiety, as any other theory of freestanding contract.

\section{The Morality Of THE Negotiation Relation}

The suggestions toward grounding no-retraction liability that appear on the face of Ben-Shahar's essay do not succeed. Nevertheless, the deeper structure of his argument implies an alternative approach to the foundations of no-retraction liability that is both more innovative and more promising. This approach comes to the surface only once in the essay, when Ben-Shahar connects no-retraction liability to "extra-legal 'no-going-back' norms in negotiations, which, for example, informally sanction a party who responds to the other party's concessions by toughening, rather than softening, her own proposals." Although Ben-Shahar does not claim so himself, these "no-goingback" norms apply quite apart from norms against bad faith or negligent negotiations; they also apply with respect to proposals that are honestly and responsibly made. These norms therefore represent a freestanding morality of the negotiation relation, which arises apart from the more general tort-like ideals that, of course, apply to this relation as well. ${ }^{45}$ The norms thus invite the inference that the foundations of a freestanding and distinctive no-retraction liability regime lie in the morality of the negotiation relation, as indeed do the foundations of orthodox contract, which is just a boundary case of this

43 Ben-Shahar, supra note 1 , at 1839.

${ }^{44}$ Id. at 1833.

${ }^{45}$ The claim that no-going-back norms reflect a freestanding moral ideal, which cannot be reduced to a special case of the duties to proceed in good faith and to avoid harming others, remains controversial, as are questions concerning the precise contours of these norms. I shall take up these questions in somewhat more detail shortly, although I do not, of course, propose to settle them. 
broader relation. I shall devote the remainder of these pages to considering this suggestion.

Although the most prominent theories of contractual obligation, including the theories involving reliance and social utility that I mentioned earlier, ${ }^{46}$ do not proceed along these lines, the idea that freestanding contractual obligation might find its grounds in the value of the relation that contracts establish among those who engage them is not unprecedented. Joseph Raz famously proposed that promises (including contractual promises) create a "special bond" among the parties to them ${ }^{47}$ and that the value of this bond might explain the distinctive character of promissory (and also contractual) obligation, including why persons feel bound to keep their promises (and also their contracts) even when doing so does not produce the best result overall. ${ }^{48}$ Raz himself was concerned exclusively with the formal properties of promissory and contractual obligation-with the ways in which these obligations fit into the patterns of persons' all-thingsconsidered, practical deliberations-and he therefore expressly made no effort to identify the substantive features of promissory and contractual relations that give these relations their value. ${ }^{49}$ The challenge for a theory of contract that proceeds along these lines, therefore, is to flesh out the contract relation so as to render plausible the claim that its value is capable of underwriting contractual obligation.

This challenge may be taken up in several different ways. One approach, most commonly associated with Ian Macneil, finds the value that underwrites contractual obligation not in the narrow contract relation itself, but rather in a host of broader relations in which contract is necessarily embedded. ${ }^{50}$ But this approach, under which contractual morality grows out of the morality of these broader relations, likely fails to capture the freestanding and distinctive character of contractual obligation that underlies the theoretical curiosity of promise and contract and to which contract theory (including Raz's contribution) sets out to respond. An alternative, nearly opposite approach

${ }^{46}$ Supra note 12 and accompanying text.

${ }^{47}$ Raz, supra note 19, at 227.

${ }^{48}$ Id. at 228.

49 See id. ("It is not my purpose to argue that the special relationships the desirability of which would validate [the promissory principles I propose] are indeed desirable. Nor will I try to explain the nature of such relationships.").

${ }^{50}$ See IAN R. MACNEIL, The New Social Contract: AN INQUiRy INTO MODERN CONTRACTUAL RELATIONS 10 (1980) (identifying "relational" contracts as those that supervene on ongoing relationships and claiming that "every contract is necessarily partially a relational contract"). 
finds the value of the contract relation in the specific web of intentions that completed, agreement-based contracts involve. I develop this approach in detail elsewhere, ${ }^{51}$ and it is the view of contract that I prefer, although it might be criticized for taking too narrow and formalist a view of the contract relation, thereby ignoring practices at the edges of contract that a successful theory must explain and abandoning resources that a successful theory should exploit. Finally, BenShahar's no-retraction principle, as evidenced by his emphasis on the morality of the negotiation relation, occupies the space between these views. Unlike Macneil's view, Ben-Shahar's account emphasizes the distinct and freestanding character of the contract relation, and unlike my approach, Ben-Shahar's account emphasizes that this relation encompasses not just the completed contractual agreement, but also the negotiations that necessarily run up to this agreement.

Contract, on all these views, presents a problem of what Bruce Ackerman calls "relational justice"-that is, of the fair management not of a lived experience, nor of a whole life, but rather of an intermediate moral category, namely an ongoing enterprise. ${ }^{52}$ A successful philosophical account of contract law along any of these lines must, first, display contract law as concerned specifically with relational justice and, second, explain why the account of contract that it proposes sets the boundaries of the contract relation in a way that makes this relation a proper site of justice. ${ }^{53}$ Ben-Shahar's essay does not, of course, achieve either of these tasks; indeed, it expressly declines, through its

${ }^{51}$ See Markovits, supra note 6, at 1448-63 (describing the patterns of intention that constitute the contractual relationship).

${ }^{52}$ Ackerman develops the idea of "relational justice" in Bruce Ackerman, Temporal Horizons of Justice, $94 \mathrm{~J}$. PHIL. 299, 304-07 (1997). He proposes this concept as a third form of justice, which arises alongside the more familiar forms of justice: corrective justice (which Ackerman associates with the lived experience) and distributive justice (which Ackerman associates with the whole life). Id. at 299. Ackerman's proposals, in this respect, are novel, and I shall not take up the question of the relationship between Ackerman's distinction among three forms of justice and the more traditional distinction between corrective and distributive justice only. Whatever it is called, and however it fits into broader frameworks of moral thought, the idea of the just regulation of an ongoing enterprise is surely intuitively compelling, and this is sufficient for present purposes.

${ }^{53}$ A successful theory must also explain why the division of benefits and burdens that it imposes on the contract relation so understood is in fact just. I shall set this question aside. In doing so, I match the emphasis of Ben-Shahar's essay, which devotes its attention almost exclusively to the conditions under which no-retraction liability applies and leaves mostly open questions of the fair measure of liability-the proper quantum of remedy. See Ben-Shahar, supra note 1, at 1844 ("The principle of noretraction can therefore be coupled with various measures of damages, depending on the underlying objective that the remedy seeks to promote."). 
disavowal of all philosophical ambition, ${ }^{54}$ to attempt anything like them.

Although I also disavow every ambition to develop a complete account of no-retraction liability as a class of relational justice, I will briefly address, or perhaps more accurately, introduce, both questions as they relate to Ben-Shahar's no-retraction view of contract. First, I will display a case in which legal doctrine may plausibly be said expressly to adopt the main lines of the boundaries of the contract relation that Ben-Shahar's account of no-retraction liability proposes. And second, I will consider whether the boundaries of this relation are properly set, as under the no-retraction principle, not at the moment of agreement nor based on preexisting practices and relations but rather, intermediately, at the moment of commencing negotiations. Each task will require elaborating on Ben-Shahar's stated account of no-retraction liability in some ways and departing from it in others. I shall try to depart from Ben-Shahar's stated views only in ways that are sympathetic to his core ambitions, although my beliefs about the proper boundaries of the contract relation differ dramatically from Ben-Shahar's, and this difference may infect some of what I say.

The proponent of the no-retraction approach to contract liability must connect this view's suggestion that the boundaries of contract should be framed in terms of the negotiation relation to the positive law of contract. Perhaps the most promising path toward making this connection expands upon Ben-Shahar's discussion of reliance-based liability under section 90 of the Restatement (Second) of Contracts. ${ }^{55}$ BenShahar focuses, properly, on Drennan v. Star Paving Co. ${ }^{56}$ in which Justice Roger Traynor held that, when a subcontractor's bid is relied upon by a general contractor in computing her own bid and the general contractor's bid is accepted, then the subcontractor's bid is irrevocable and binds him, even though it has not been accepted by the general contractor. ${ }^{57}$ Ben-Shahar presents the holding as evidence that "the law already recognizes mild versions of a no-retraction principle, ${ }^{58}$ but this massively understates the importance of the case to Ben-Shahar's view. In fact, Drennan may be understood as expressly

${ }^{54}$ See supra text accompanying note 5 (citing Ben-Shahar's express intention to omit discussion of the philosophical foundations underlying no-retraction liability).

${ }^{55}$ RESTATEMENT (SECOND) OF CONTRACTS $\$ 90$ (1981).

${ }^{56} 333$ P.2d 757 (Cal. 1958).

${ }^{57}$ Id. at 760.

${ }^{58}$ Ben-Shahar, supra note 1, at 1866. 
rejecting the orthodox view of the contract relation in favor of something like Ben-Shahar's approach-as expressly recognizing that contractual liability can arise not only out of the narrow agreement relation, but also, as Ben-Shahar proposes, out of the broader negotiation relation.

This is made clear not by Drennan itself, but by the contrast between Drennan and an earlier section 90 case, James Baird Co. v. Gimbel Bros. $^{59}$ In Gimbel Bros., Judge Learned Hand, facing almost perfectly analogous facts, declined to bind a subcontractor to his offer. ${ }^{60}$ Hand reasoned that, although section 90 serves to make relied-upon promises binding even in the absence of consideration, it governs only promises proper and therefore does not apply to the subcontractor's unaccepted bid, which remained a mere offer. ${ }^{61}$ The difference between Hand's and Traynor's views illustrates the central interpretive question about section 90 reliance, namely whether it merely relaxes the consideration doctrine in connection with completed promises or whether, instead, it frees the law of contract from the promise requirement altogether. Gimbel Bros. takes the former, narrower view, while Drennan (and much of the subsequent law) takes the latter, broader view. The possibility of the broad view impelled Grant Gilmore, analogizing to anti-matter, to call section 90 "anti-Contract." Ben-Shahar's theory of no-retraction liability, by contrast, fits the broad view seamlessly into contract liability. Drennan suggests that the main thrust of Ben-Shahar's view-the proposal to replace the agreement relation with the negotiation relation at the core of contracthas been expressly welcomed into the law of contract.

The proponent of the no-retraction view of contract liability cannot rest at showing that contract law recognizes not only completed agreements, but also the broader negotiation relation. She must additionally establish the boundaries of the negotiation relation-how the relation is entered and exited-in a manner that renders this relation a plausible site of relational justice. A successful philosophical elaboration of no-retraction liability will have to depart from Ben-Shahar's account of the boundaries of the negotiation relation in both respects. First, Ben-Shahar's account brings activities within the scope of noretraction liability that do not qualify, in any natural or intuitive sense, as establishing a relation among their participants at all. Second,

\footnotetext{
${ }^{59} 64$ F.2d 344 (2d Cir. 1933).

Id. at 346 .

${ }^{61} I d$.

${ }^{62}$ Grant Gilmore, The DeATh OF CONTRACT 61 (12th prtg. 1982).
} 
Ben-Shahar's account fails to recognize adequate possibilities for exiting the negotiation relation. Neither shortcoming requires abandoning Ben-Shahar's basic insight that contractual obligations arise not just in connection with completed agreements, but also in connection with broader negotiations. At the same time, each shortcoming requires modifying some of Ben-Shahar's stated positions.

To begin with, consider the question of entering the negotiation relation and thereby becoming subject to no-retraction liability. BenShahar worries, properly, that, if no-retraction liability sweeps too broadly-if, in the extreme case, the failure expressly to refuse to deal is treated as a representation of a willingness to deal-then property rules will be quite generally converted to liability rules, and persons will be at risk of being involuntarily deprived of their holdings, albeit at prices so favorable to them as to compensate for any economic losses involved. ${ }^{63}$ Ben-Shahar sensibly wishes to avoid this outcome (which might be taken as a reductio ad absurdem of the no-retraction principle), and he therefore suggests that no-retraction liability be triggered only by representations that provide enough detail to infer the proposer's intent to contract under their terms. ${ }^{64}$ This liability will tend, initially, not to be very burdensome to proposers because any gaps in their representations will be filled in with terms that are as favorable to them as they could reasonably wish. But even so, BenShahar's test remains too quick to apply the no-retraction principle, and the liability it generates will often exceed all plausible limits.

To see the problem, one need only imagine that a seller issues a general solicitation for offers to buy and ask whether this general solicitation is enough to allow a buyer, asserting the no-retraction principle, to bind the seller to sell at the highest reasonable price. Such liability seems clearly misplaced-in fact, almost unimaginable. ${ }^{65}$ This

${ }^{63}$ Ben-Shahar, supra note 1 , at 1843 .

${ }^{64}$ Id. at $1843-44$.

${ }^{65}$ Certainly the law unambiguously rejects liability in such cases, for example, when it treats advertisements not as offers but as invitations to deal and therefore renders them generally unenforceable even if "accepted" See, e.g., RESTATEMENT (SECOND) OF CONTRACTS $\$ 26 \mathrm{cmt}$. b (1981) ("Advertisements of goods by display, sign, handbill, newspaper, radio or television are not ordinarily intended or understood as offers to sell.").

Ben-Shahar does wonder to whom such liability might be owed in this type of case, and he worries that the no-retraction principle must be formulated in such a way that a person who makes concurrent proposals is not held liable to many partners when she intended to deal with just one. See Ben-Shahar, supra note 1, at 1867 ("Another concern has to do with a party's ability to make concurrent proposals to numerous potential partners, where a contract can be entered into with, at most, one of the 
is especially true given that no-retraction liability is strict liability ${ }^{66}$ so that it will apply not only to representations issued in bad faith or negligently, but also, and characteristically, to honest and responsible representations, whose authors have, for good reason, simply changed their minds. Moreover, these intuitions may be supported and refined by approaching such cases in light of the no-retraction principle's roots in relational justice. The suggestion that a general invitation to deal might give rise to no-retraction liability falters because, even when it is seriously intended, such a general invitation plainly does not yet open negotiations with anyone. No-retraction liability is grounded in the relational justice of the negotiation relation and so cannot arise except in connection with this relation. If Ben-Shahar is to make use of the ideas of relational justice that provide the most promising philosophical foundations for his principle of noretraction, he must adjust his claims about the beginnings of noretraction liability to produce a more intuitively compelling account of the boundaries of the negotiation relation in which this liability arises. $^{67}$

respondents."). Ben-Shahar solves this problem by stipulating that a retraction occurs, in such a case, only if the proposer rejects all responses and not if she rejects responses after having accepted one. Id. at 1868. Ben-Shahar does not, however, consider the other worry that this case triggers, namely, that it is unnatural to treat a person who makes an open proposal as commencing negotiations with anyone at all.

${ }^{66}$ Strict liability is required, remember, in order for the no-retraction principle to underwrite a theory of contract and not just an account of certain special cases of the tort of misrepresentation.

${ }^{67}$ A similar argument may be made in connection with Ben-Shahar's treatment of no-retraction liability in the context of mutual mistake, in particular in his discussion of the Peerless case. Raffles v. Wichelhaus, 159 Eng. Rep. 375 (Ex. 1864). A buyer and seller contracted for the sale of a shipload of cotton to be carried by the ship Peerless. $I d$. at 375. As it turned out, there were two ships named Peerless, one that sailed in October and one that sailed in December, and while the buyer had, innocently, known only of the October ship, the seller had, also innocently, known only of the December ship. Id. The court, citing the lack of mutual assent, found no contract, $i d$. at 376 , and this result has been codified in the Restatement, RESTATEMENT (SECOND) OF CONTRACTS $\$ 20$ illus. 1-2 (1981).

Ben-Shahar rejects this result and suggests, instead, that, under the no-retraction principle, each party should be entitled to enforce a contract in accordance with the terms intended by the other. Ben-Shahar, supra note 1, at 1838. This proposal seems dubious, however. It is not hard to imagine that one, or indeed both, of the parties comes, innocently, to regret the deal it had intended to make. The October market price may fall below the contract price, and the December market price may rise above it. Ben-Shahar's approach would allow each party to burden the other with a deal she now regrets. While it may be that this rule will, on some facts, distribute the costs of the mistake more equally than the law's refusal to enforce any contract (Ben-Shahar suggests that this would have been true on the actual facts of the Peerless case, id. at $1856 \& \mathrm{n.58}$ ), there is no reason to think that it would in general distribute these costs 
Finally, a successful philosophical account of no-retraction liability must develop an adequate theory of exiting the negotiation relation. Although Ben-Shahar draws his examples disproportionately from cases involving bad faith, these cases do not in fact exhaust the scope of no-retraction liability, which, as a species of strict liability, instead extends to efforts to withdraw even representations that were honestly and responsibly made. ${ }^{68}$ And precisely because no-retraction liability potentially applies so broadly, other limits on its scope must be established in order to render it plausible. It may happen, for example, that the slow pace of convergence causes one party to conclude that the final deal will not be worth its transaction costs and therefore to withdraw its last offer and abandon the negotiation altogether. ${ }^{69}$ It seems implausible, once again, to suppose that the other party can, in such circumstances, apply no-retraction liability to enforce this last offer, and this skeptical intuition is confirmed by the everyday morality of bargaining out of which, I have suggested, no-retraction liability arises. These everyday intuitions distinguish between retractions that are accompanied by attempts to continue negotiating on more aggressive terms and retractions that are meant to abandon negotiations entirely. Moreover, such intuitions find a natural purchase in the more abstract morality of the negotiation relation, which, I have suggested, grounds no-retraction liability: They pick out the distinction between betraying a negotiation and merely dissolving it. A successful philosophical defense of no-retraction liability, understood as a species of relational justice applied to the negotiation relation, must flesh out the contours of this relation, in respect of its endings, in a way that gives theoretical expression to these intuitive distinctions.

more fairly. Indeed, the unfairness in the Peerless case arose only because of a contingent feature of the facts of the case, namely, that the two mistakes were not revealed at the same time, so that the buyer could take advantage of the seller's mistake, whereas the seller could not take advantage of the buyer's. Moreover, insofar as no-retraction liability finds its grounds in the morality of the negotiation relation, it is entirely plausible to say that no-retraction liability does not arise in such cases because the two parties failed in fact to find a subject over which to negotiate. Their intentions to negotiate both missed their marks, as it were, so that no true negotiation ever arose.

I am not, of course, claiming that these remarks constitute the last word concerning no-retraction liability and mutual mistake; I am suggesting only that the question may be profitably approached by investigating the character and boundaries of the negotiation relation.

${ }^{68}$ Indeed, insofar as bad faith in retracting a negotiating position tends to be associated with misrepresentation in making it, cases of bad faith retractions invoke tortlike, rather than freestanding contractual, ideals, and they are therefore neither representative, nor characteristic, of no-retraction liability.

${ }^{69}$ I owe this example to Alan Schwartz. 
Omri Ben-Shahar's Contracts Without Consent develops a principle of no-retraction liability that constitutes an intriguing new approach to an old and familiar problem. Although Ben-Shahar's essay does not advertise the philosophical foundations of his conception of contract, his ideas may be reconstructed to reveal a novel effort to ground contractual obligation in the relational justice of negotiations. Such a reconstruction requires abandoning some of Ben-Shahar's professed views about the morality of no-retraction liability and modifying some of his proposals concerning the doctrinal details of this regime, but the reconstruction nevertheless remains true to the main lines of BenShahar's approach.

Further investigation of Ben-Shahar's ideas should elaborate the intuitive understanding of negotiation that lies at the root of his theory of contract into a theoretically satisfying account of this relationship and of the principles of relational justice that govern it. I have tried, in these pages, to point to some of the main lines of argument that this elaboration will involve by focusing on the boundaries of the negotiation relation-its beginnings and endings. A successful philosophical reconstruction of Ben-Shahar's views will also have to defend the broad view of the negotiation relation against alternative conceptions of the scope of contract. In particular, it will have to address the view that I prefer, which insists that only completed agreements possess the moral significance needed to generate principles of relational justice capable of grounding contractual obligation. This narrower view's emphasis on the completed agreement relation is neither arbitrary nor stingy, but instead focuses attention on the distinctive web of intentions that the agreement relation involves-in particular, the intentions of each party to subject its future conduct to the authority of the other-and argues that these intentions are essential to contract's claim to present a freestanding site of relational justice. No analogous intentions exist in negotiations simpliciter, and a successful philosophical reconstruction of Ben-Shahar's views will have to explain why negotiations nevertheless constitute a relation to which relational justice properly applies. 
* * * * * * *

HeinOnline -- 152 U. Pa. L. Rev. 1922 2003-2004 


\section{JASON SCOTT JOHNSTON ${ }^{\dagger}$}

In Contracts Without Consent: Exploring a New Basis for Contractual Liability, ${ }^{1}$ Omri Ben-Shahar, a talented and creative economic analyst of law, advocates a principle-which he calls the "no-retraction" principle ${ }^{2}$ - that is so at odds with the existing structure of the common law of contracts ${ }^{3}$ as to basically turn contract law upside down. BenShahar's no-retraction principle would radically alter the line between agreement and no agreement, between liability for unkept promises or assurances and no liability for such unkept promises or assurances. Indeed, under a no-retraction regime, there would be no line between agreement and no agreement, and contractual liability could exist even in the absence of any communication (or what Ben-Shahar calls a "proposal") ${ }^{4}$ at all. Transactions could be forced upon parties who want nothing to do with them-either because they've walked away from failed negotiations or because they were never in any negotiations to begin with-but only on the terms that were or would have been demanded by the unwilling party. By incurring reliance expenditures early in a contractual negotiation (or, apparently, before a negotiation had even begun), a relying party could hold the other negotiating party liable for those reliance expenses, regardless of

${ }^{\dagger}$ Robert G. Fuller, Jr. Professor of Law and Director, Program on Law and the Environment, University of Pennsylvania Law School.

${ }^{1}$ Omri Ben-Shahar, Contracts Without Consent Exploring a New Basis for Contractual Liability, 152 U. PA. L. REv. 1829 (2004).

${ }^{2}$ See id. at 1838-53 (explaining the reasoning behind and the benefits of this principle).

${ }^{3}$ Inasmuch as " $[t]$ he central tenet of the civil law . . . is that promissory estoppel does not exist," David V. Snyder, Comparative Law in Action: Promissory Estoppel, the Civil Law, and the Mixed Jurisdiction, 15 ARIz. J. INT'L \& COMP. L. 695, 703 (1998), the noretraction regime is even more baldly inconsistent with the civil law basis for promissory liability. See also JOHN P. DAwSON, GIFTS AND Promises: CONTINENTAL AND AMERICAN LAW COMPARED 88-90, 188-91 (1980) (discussing the failure of either French or German courts to attach independent significance to detrimental reliance as a basis for promissory enforcement).

${ }^{4}$ Ben-Shahar, supra note 1, at 1831 (referring to "precontractual representations of ... proposed terms" as "proposal[s]"). 